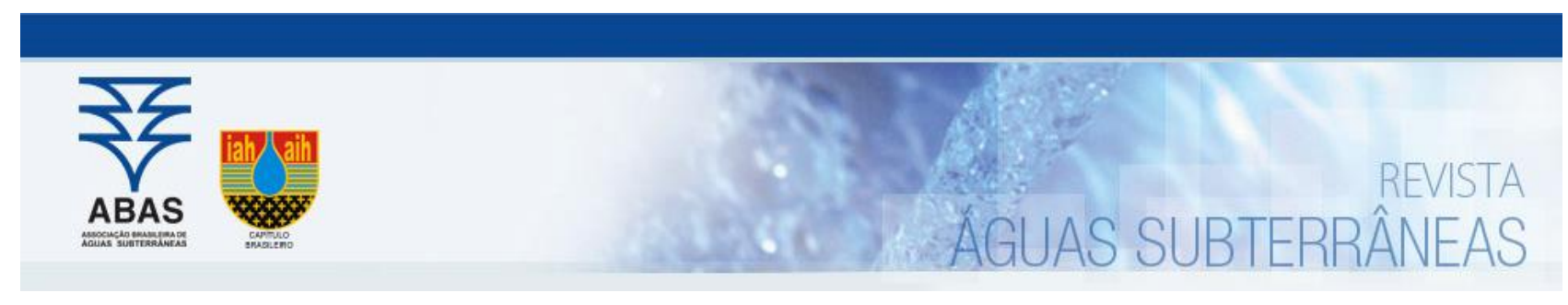

\title{
Artigos
}

\section{Prospecção Hidrogeológica Regional para Águas Minerais}

\author{
Regional Hydrogeological Prospection for Natural Mineral Water
}

\author{
Giancarlo Pinto Saraiva1; Didier Gastmans; Lucas Vituri Santarosa ${ }^{1 \varpi}$ \\ 1 Universidade Estadual Paulista "Julio de Mesquita Filho" (UNESP) - Centro de Estudos Ambientais (CEA), São Paulo, SP. \\ $\bowtie$ giancarlo.saraiva@gmail.com, didier.gastmans@unesp.br, lucas.santarosa@unesp.br
}

\begin{abstract}
Palavras-chave:
Águas Minerais.

Prospecção Hidrogeológica.

Sistema Aquífero Guarani.
\end{abstract}

Keywords:

Natural Mineral Water. Hydrogeological Prospection. Guarani Aquifer System.

Revisão por pares. Recebido em: 30/11/2020. Aprovado em: 16/03/2021.

\begin{abstract}
Resumo
O estudo propõe um modelo para a prospecção hidrogeológica de água mineral em escala regional, voltada à seleção preliminar de áreas alvo para a implantação de projetos de águas minerais. Para isso, foram considerados como parâmetros prospectivos: capacidade específica; espessura do aquífero; grau de confinamento; recarga potencial; densidade de poços; caracterização econômica (renda e tamanho do mercado local); além da caracterização hidroquímica, incluindo parâmetros que indicam a sua mineralização (condutividade elétrica), qualidade (nitrato) e classificação quanto ao potencial mineral (fluoreto). Todas as informações dos parâmetros selecionados foram avaliadas individualmente por meio da construção de mapas temáticos e estatisticamente. A partir da ponderação desses parâmetros, foi desenvolvido um modelo metodológico de prospecção, que aponta, por meio do ranqueamento de áreas, os alvos a serem priorizados em uma campanha exploratória detalhada. Para validação, o modelo foi aplicado na área representada pelos municípios com afloramentos de rochas do Sistema Aquífero Guarani (SAG) no estado de São Paulo, resultando em um ranqueamento da potencialidade e favorabilidade mineral, a serem priorizados em uma campanha de pesquisa detalhada.
\end{abstract}

Abstract

This study proposes a model for hydrogeological assessment and prospection of natural mineral water on a regiona scale aimed to select potential areas for implementing natural mineral water projects. The following prospective parameters were used to develop this model: specific capacity; aquifer thickness or geological water reservoir unit; degree of aquifer confinement; potential recharge; well density; economic characterization (size of the consumer market and income); in addition to the characterization and hydrochemical profile, based on the degree of mineralization, evaluated based on electrical conductivity, water quality (nitrate) and classification according the mineral potential (fluoride). The information from the selected parameters were evaluated individually through thematic maps and statistically. These parameters were weighted according their importance in the model, that served as the basis for the development of a methodological natural mineral water prospecting model whose result was given through ranking with target areas to be prioritized in a detailed exploratory campaign. In order to validate the model, it was applied in to the area represented by the municipalities with outcrops of rocks from the Guarani Aquifer System (SAG) in the state of São Paulo, resulting in a ranking of potentiality and mineral favorability, pointing out target areas to be prioritized in a detailed research campaign.

\section{INTRODUÇÃO}

A água mineral é um bem mineral relevante para o Brasil, representando, no ano de 2019 , a $8^{\circ}$ substância mineral de maior arrecadação de CFEM (Compensação Financeira pela Exploração de Recursos Minerais) (ANM, 2018). O país possui importantes aquíferos produzindo águas em quantidade e qualidade relevantes, corroborando para a necessidade de estudos que subsidiem a correta avaliação de seu potencial mineral.

0 aumento do consumo de águas minerais no Brasil (2013-2018) da ordem de 4,8\% alcançou, em 2018, uma produção de 22,8 trilhões de litros, representando cerca de $6,2 \%$ do volume total global, tornando o país o $5^{\circ}$ maior mercado consumidor mundial (RODWAN JR., 2019). O estado de São Paulo produz cerca de 20,8\% das águas envasadas no país, seguido pelos estados de Pernambuco (9,3\%), Bahia (7,0\%) e Ceará (6,5\%) (ANM, 2018). Ao final de 2017 existiam 1.205 Concessões de Lavra de água mineral e potável de mesa, distribuídos em 567 complexos produtivos de água mineral e fabricação de bebidas no país, e destes, 151 localizados em São Paulo (ANM, 2018).

No Brasil, o aproveitamento de águas minerais, de acordo com o Código de Águas Minerais (Decreto Lei ${ }^{\circ}$ 7.841, de 08/08/1954), depende de Autorização ou Concessão da União Federal por meio de Portaria de Lavra, que a classifica conforme suas características per- 
manentes (composição química, presença de oligominerais e propriedade físico-químicas) ou das fontes (gases e temperatura) (BRASIL, 1945).

Embora a caracterização e evolução hidroquímica das águas minerais envasadas seja vastamente estudada, tanto no Brasil (BERTOLO et al., 2007; REIS, 2011; BONOTTO, 2014; GARPELLI et al., 2020) quanto mundialmente (VIRGÍlIO CRUZ et al., 2010; LOURENÇO et al., 2010; BODIŠ et al., 2010; BITYUKOVA et al. 2010; LYUBOMIROVA et al., 2020), pouca literatura sobre técnicas de prospecção mineral focada em águas minerais existe, havendo uma lacuna técnica e de conhecimento a ser preenchida.

O principal objetivo do estudo foi o desenvolvimento de uma abordagem voltada à prospecção hidrogeológica regional, por meio de uma análise combinada de parâmetros que possibilitaram a criação de um ranqueamento de favorabilidade que determine alvos prioritários para pesquisa pontual detalhada, visando a implantação de projetos industriais. Essa abordagem foi aplicada nos municípios que possuem afloramentos de rochas do Sistema Aquífero Guarani (SAG), no estado de São Paulo, devido às suas características hidrogeológicas e hidroquímicas específicas, que favorecem a exploração voltados ao mercado de águas minerais.

Pretende-se que o modelo proposto seja replicável a outros cenários, aquíferos e/ou perfis específicos de águas para campanhas exploratórias hidrogeológicas, bem como subsidie a discussão de uma nova forma de desenvolvimento de projetos deste bem mineral, baseada em uma visão técnica e científica.

\section{METODOLOGIA PARA O DESENVOLVIMENTO DO MO- DELO DE PROSPECÇÃO}

Metodologias para prospecção mineral focadas em minérios metálicos e não metálicos são conhecidas (MARANHÃO, 1985; PEREIRA, 2003; MELFI, MISI, CAMPOS, CORDANI, 2016); entretanto, a prospecção mineral sistematizada de águas minerais ainda é pouco abordada, uma vez que o aproveitamento econômico está relacionado a ocorrências conhecidas, como fontes e surgências naturais.

Avaliar a potencialidade mineral em escala regional requer a análise de um grande volume de dados, além do uso de simplificações para a determinação de municípios "alvos", que se caracterizam por serem mais propícias ao desenvolvimento de um projeto de água mineral, e que contemple: alta produtividade, excelente qualida- de e baixo risco de contaminação antrópica.

Para o desenvolvimento do modelo de prospecção mineral hidrogeológica regional foram selecionados nove parâmetros exploratórios prioritários, considerando aspectos econômicos, hidrogeológicos, hidroclimatológicos, geológicos e hidroquímicos.

A viabilidade econômica de um projeto hidromineral é um aspecto importante para uma indústria de águas minerais. Devido ao valor final do produto ser relativamente baixo, a distância do mercado consumidor (frete) é essencial para a viabilização do negócio. Desta forma, para a definição do "Aspecto Econômico (AE)", foram considerados: o potencial do mercado consumidor (população) e a renda per capita desse mercado (por município). Este parâmetro foi calculado de acordo com a equação:

$A E=\frac{(7 * \text { População })+(3 * \text { PIB capita })}{10}$

Bancos de dados hidrogeológicos regionais permitem a obtenção de informações hidrogeológicas e geológicas a serem utilizadas como parâmetros exploratórios, como a produtividade (vazão e vazão específica) e densidade de poços, geometria do aquífero e seu grau de confinamento, profundidade da água e fluxo subterrâneo.

A produtividade dos poços pode ser estimada a partir da sua vazão específica $(\mathrm{Q} / \mathrm{s})$, pois correlacionam a descarga do poço com o rebaixamento decorrente (FEITOSA et al., 2008). Por ser um parâmetro importante no modelo de prospecção hidrogeológico proposto, foi atribuída uma ponderação superior para este parâmetro.

Para a espessura do aquífero, por caracterizar a disponibilidade de minério, recebeu uma ponderação superior no modelo de prospecção.

O estágio de explotação de um aquífero pode ser avaliado a partir da densidade de poços existentes em uma determinada área. Por indicar um potencial risco de superexplotação, com interferência entre os poços através dos seus respectivos cones de depressão e competição com o empreendimento mineral, é um parâmetro importante a ser considerado no modelo, tanto para a viabili dade do empreendimento quanto para a gestão dos re cursos hídricos.

A proteção das águas subterrâneas ao risco de contaminação, conferido pelo confinamento do aquífero, é importante, pois a alteração na qualidade das águas 
subterrâneas pode resultar na não conformidade dos requisitos físico-químicos e microbiológicos (BRASIL, $2005 a$ e 2005b) resultando na descaracterização para sua finalidade mineral. Nesse sentido, aquíferos confinados tendem a estar menos suscetíveis a impactos, pela presença de camadas impermeáveis sobrepostas, assim como aquíferos livres são mais vulneráveis (FEITOSA et al., 2008). No presente modelo, em bacias sedimentares, a presença destes litotipos é fator positivo para um projeto de águas minerais; mas, por outro lado, grandes espessuras destas camadas podem elevar consideravelmente os custos de perfuração, instalação e manutenção de poços.

A renovação das reservas de água subterrânea é característica importante para a gestão sustentável do empreendimento a médio e longo prazo, e o reconhecimento de regiões com maiores taxas de recarga auxilia na seleção de áreas potenciais.

Atualmente existem diversas metodologias utilizadas na estimativa da recarga de aquíferos, como: (i) modelos empíricos espaciais com base em equações de balanço hídrico; (ii) análises a partir da separação do hidrograma; (iii) balanço de massa de cloretos; (iv) utilização de traçadores naturais (isotópicos ou químicos); e (v) variações no armazenamento do aquífero (SCANLON et al., 2002; HEALY, 2010).

Para a avaliação da mineralização e qualidade das águas subterrâneas foram utilizados como parâmetros exploratórios, a condutividade elétrica (grau de mineralização), íon nitrato (qualidade) e íon fluoreto (aproveitamento mineral). Em função da baixa disponibilidade de bancos de dados hidroquímico para a área de aplicação deste modelo, esta avaliação foi realizada em uma etapa complementar denominada aqui de refinamento.

Sendo de senso comum, a popularidade dos consumidores brasileiros por águas minerais de baixa mineralização, devido a sua leveza, foi considerada uma faixa "ótima" para esse parâmetro valores de CE entre 60 e $120 \mu \mathrm{S} / \mathrm{cm}^{2}$, valores que englobam a maioria das águas consumidas no Brasil (QUEIROZ, 2015).

Por ser indicativo de qualidade das águas subterrâneas, o íon nitrato $\left(\mathrm{NO}_{3}{ }^{-}\right)$foi incluído como parâmetro na pesquisa exploratória. Ele ocorre naturalmente apenas em pequenas concentrações nas águas subterrâneas, com backgrounds que variam de $9 \mathrm{mg} / \mathrm{l}$ em regiões florestais dos EUA (MUELLER \& HELSEL, 1996), a $3 \mathrm{mg} / \mathrm{l}$ em áreas urbanas no estado de São Paulo (CAGNON \& HIRATA, 2004) e seu padrão de qualidade da água para fins de abastecimento e consumo humano é especificado como 10 mg/l (como N-NO3-) sendo o limite aceitável para este elemento em águas subterrâneas (BRASIL, 2017). Desta forma, para o modelo exploratório foi considerado um valor "ótimo" para águas com concentrações de nitrato inferior a 2 mg/l e "não aceitáveis" valores superiores a $5,0 \mathrm{mg} / \mathrm{l}$.

Observa-se que no estado de São Paulo, aproximadamente $86 \%$ de todas as águas minerais são classificadas como fluoretadas e/ou fluoretadas e combinações (QUEIROZ, 2015). A presença deste íon dentro dos limites preconizados pelo Código de Águas Minerais (BRASIL, 1945), doravante denominado CAM, é uma referência prática para a prospecção hidrogeológica, possibilitando a classificação das águas como um bem mineral. Os principais parâmetros e critérios exploratórios utilizados para o desenvolvimento deste modelo de prospecção são apresentados no fluxograma da Figura 1, onde é possível associar as análises e critérios técnicos/estatísticos empregados no modelo, que a partir de uma análise estatística exploratória, atribui uma pontuação variável (1 a 10) para cada parâmetro avaliado. Para a definição do ranqueamento final das áreas é realizada a somatória das pontuações por munícipio.

Foram considerados "ótimos" aqueles municípios que apresentaram valores acima do $3^{\circ}$ quartil estatístico para os aspectos econômicos, capacidade específica, espessura de aquífero e recarga, indicando assim alto potencial econômico e hídrico destes municípios. 0 grau de confinamento foi considerado "ótimo" quando apresentaram valores entre os $2^{\circ}$ e $3^{\circ}$ quartis estatístico, determinando assim, menor vulnerabilidade das águas subterrâneas sem elevados custos de implementação e manutenção do projeto com a perfuração dos poços em grandes profundidades. Já, a densidade de poços foi classificada como "ótima”, quando possuiu valores inferiores ao $1^{\circ}$ quartil estatístico, associando-se assim a menores riscos potenciais de suprexplotação e conflitos.

Para a classificação e o ranqueamento final dos municípios e assim a determinação dos alvos prioritários, foram considerados como "ótimos" aqueles que apresentaram a pontuação final superior ao $3^{\circ}$ quartil estatístico.

Para a integração de todas as informações ranqueadas, a partir dos critérios de avaliação e priorização definidos, foi utilizada plataforma GIS, para o fornecimento da análise especializada por meio de mapas temáticos e de favorabilidade. 
Figura 1 - Critérios exploratórios estabelecidos dentro da proposta metodológica para caracterização e categorização de áreas quanto à favorabilidade para águas minerais

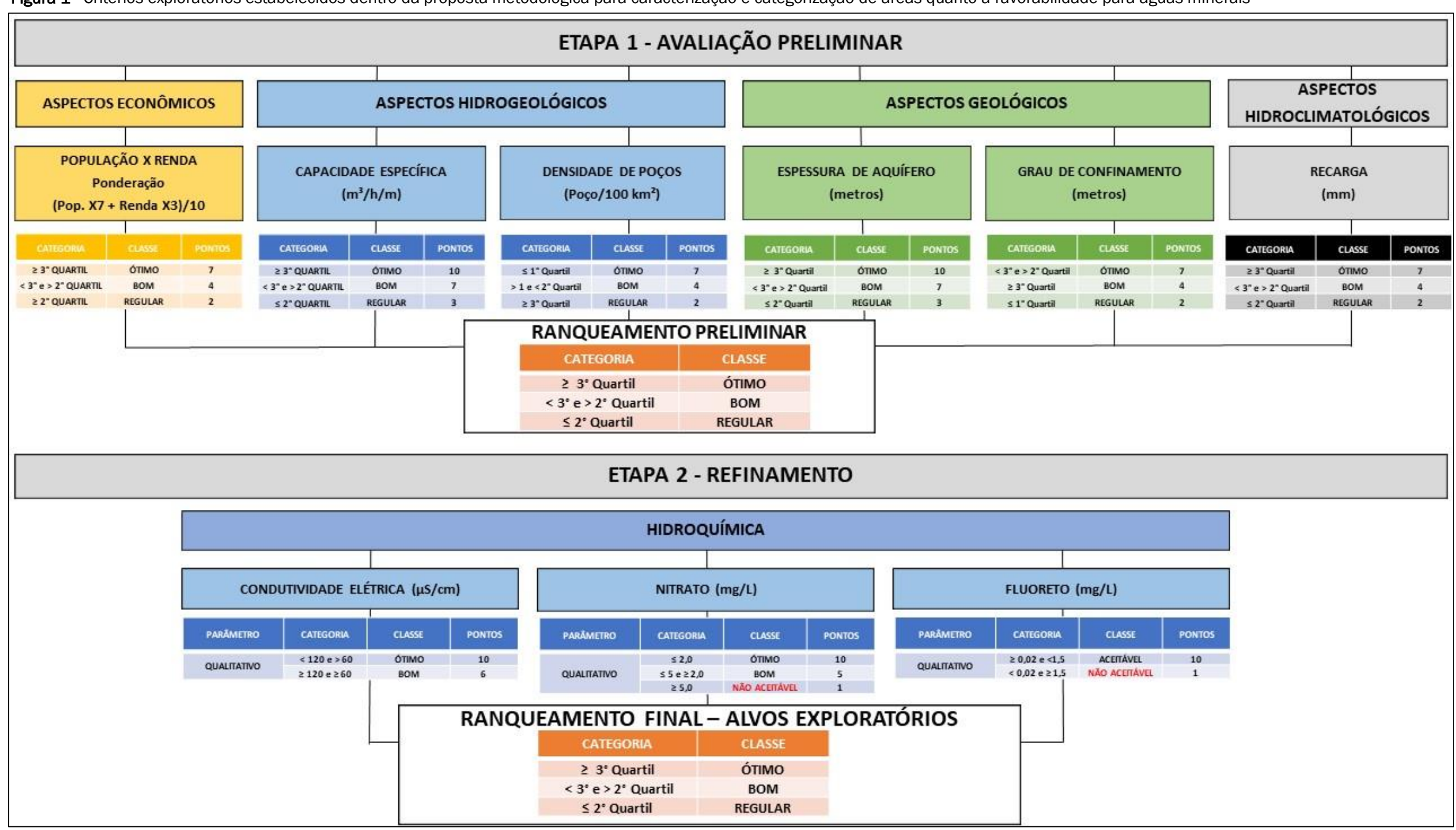




\section{CARACTERIZAÇÃO DA ÁREA DE APLICAÇÃO DO MO- DELO}

A aplicação do modelo proposto é uma etapa necessária para sua validação, e para tanto, foi selecionada a área referente aos 93 municípios que possuem afloramentos de rochas do SAG no estado de São Paulo, e ocupa uma área aproximada de 16.000 km², (6,2\% da área total do estado), e população aproximada de $4 \mathrm{mi}$ Ihões de habitantes (cerca de $10 \%$ da população do estado). A base de avaliação utilizada no modelo foi a divisão dos municípios, e para valores especializados foi utilizada o valor médio para cada parâmetro considerado.

A área de aplicação do modelo no estado no São Paulo é representada pela ocorrência das formações Piramboia e Botucatu, e localiza-se próxima a borda oeste da Depressão Periférica Paulista, constituindo-se em um aquífero granular, homogêneo e regionalmente livre.

A área de estudo situa-se na transição entre as zonas de climas Subtropical Quente a Tropical, e localmente, a Subtropical Temperado e Tropical com chuvas excessivas (SANTOS et al., 2012), com índice pluviométrico médio anual de $1.476 \mathrm{~mm} / \mathrm{ano}$, variando de $1.240 \mathrm{a}$ 2.122 mm/ano, respectivamente em Porangaba e Brodowski (DAEE, 2020).

O quadro litoestratigráfico do SAG na área é composto pelos arenitos continentais mesozoicos das formações Botucatu e Piramboia, e o seu substrato representado pelos siltitos e argilitos da Formação Corumbataí de idade Permiana, depositada em ambiente de sedimentação essencialmente marinho (Figura 2).

A Formação Piramboia está assentada discordantemente sobre a Formação Corumbataí (discordância Permo-Eotriássica), e seu ambiente deposicional é caracterizado pela predominância de deposição eólica sobre a deposição fluvial, com diferentes associações de fácies de duna, interduna e de lençóis de areia que por vezes apresentam interação com depósitos de canais fluviais e planícies de inundação (CAETANO-CHANG, 1997).

A Formação Botucatu é caracterizada predominantemente por arenitos finos a médios, friáveis, quartzosos, bem arredondados, bem selecionados e com estratificações cruzadas de grande e médio porte, depositados em ambiente desértico, tendo sofrido grande influência dos processos eólicos com fácies de depósitos torrenciais e provenientes de depósitos lacustres (PAULA e SILVA et al., 2008).

Sobre os arenitos do SAG, encontram-se o conjunto de derrames de rochas basálticas e magmatitos intrusivos da Formação Serra Geral, constituída por basaltos toleíticos e andesitos basálticos com quantidades subordinadas de riolitos e riodacitos (PEATE et al, 1992). A recorrência de arenitos nas camadas inferiores dos basaltos da Formação Serra Geral assinala a contemporaneidade entre a sedimentação eólica da Formação Botucatu e os primeiros derrames de lavas (PAULA e SILVA et al., 2008).

As águas subterrâneas dos municípios que possuem afloramentos de rochas do Sistema Aquífero Guarani são predominantemente bicarbonatadas magnesianas e calco-magnesianas a bicarbonatadas cálcicas e calcomagnesianas (SILVA, 1983). Na área de estudo o gradiente hidráulico médio está entre 0,008 e 0,003 e os arenitos possuem condutividade hidráulica média de 3,0 m/dia com porosidade efetiva média de 0,17 e transmissividade média de $260 \mathrm{~m}^{2} /$ dia (DAEE, 1974), com poços apresentando vazões entre 20 e $40 \mathrm{~m}^{3} / \mathrm{h}$ (DAEE/IG/IPT/CPRM, 2005) com fluxo das águas subterrâneas, para oeste, em direção ao Rio Paraná (GASTMANS et al., 2012).

\subsection{Aspectos Socioeconômicos}

A avaliação socioeconômica dos 93 municípios foi realizada a partir dos dados oficiais do IBGE (Instituto Brasileiro de Geografia e Estatística - População Estimada 2019), bem como o Atlas do Desenvolvimento Humano no Brasil (Programa das Nações Unidas para o Desenvolvimento - PNUD, 2013), Instituto de Pesquisa Econômica Aplicada (IPEA) e Fundação João Pinheiro Brasil, utilizando-se a Equação 1 para a quantificação do parâmetro.

Os resultados permitiram classificar como ótimos 25 municípios (valores $\geq 0,86$ ), enquanto 19 municípios foram considerados bons (valores entre 0,86 e 0,58) e 49 municípios considerados "regulares" (valores $\leq 0,58$ ). Os municípios com melhor classificação segundo esse critério são apresentados na Tabela 1. 
Figura 2 - Mapa geológico dos municípios que possuem afloramentos de rochas do Sistema Aquífero Guarani no estado de São Paulo (Modificado de DAEE-UNESP, 1984). São indicados os munícipios considerados para a aplicação do modelo de prospecção, bem como os poços utilizados do banco de dados do SIAGAS, 2019. Obs: Sistema Aquífero Bauru (SAB), Sistema Aquífero Serra Geral (SASG), Sistema Aquífero Guarani (SAG), Aquiclude Passa Dois (APD) e Sistema Aquífero Tubarão (SAT)

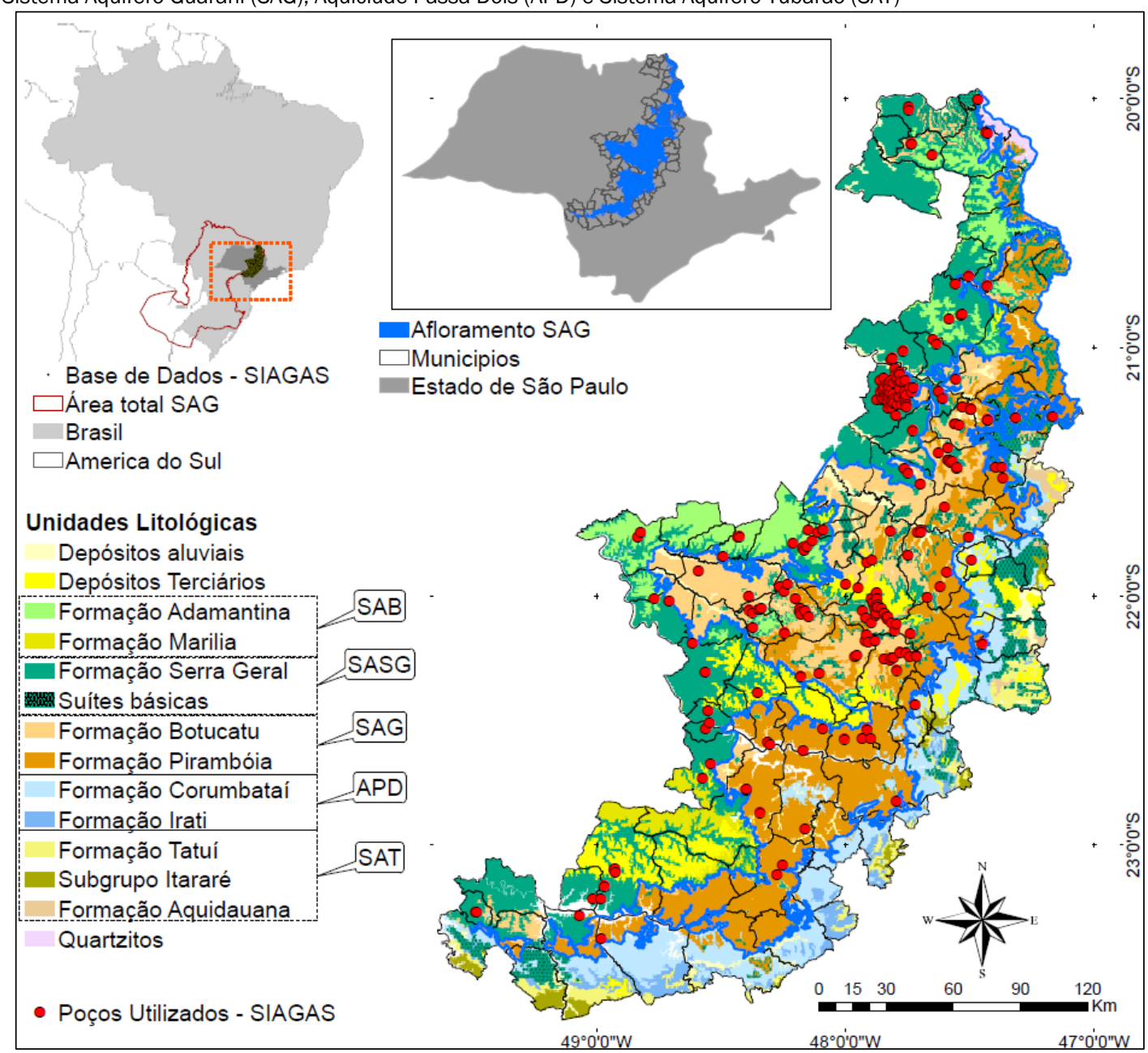

Tabela 1 - Ranqueamento dos 10 principais municípios na área de estudo, segundo o parâmetro socioeconômico

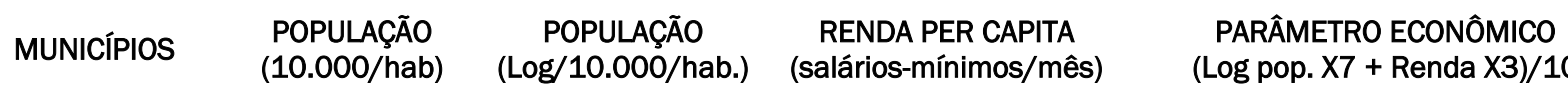

\begin{tabular}{ccccc}
\hline Ribeirão Preto & 70,33 & 1,85 & 2,58 & 2,07 \\
Piracicaba & 40,41 & 1,61 & 2,30 & 1,81 \\
São Carlos & 25,20 & 1,40 & 2,12 & 1,62 \\
Araraquara & 23,61 & 1,37 & 2,12 & 1,60 \\
Franca & 35,32 & 1,55 & 1,69 & 1,59 \\
Rio Claro & 20,64 & 1,31 & 2,06 & 1,54 \\
Botucatu & 14,65 & 1,17 & 2,14 & 1,46 \\
Jaú & 15,03 & 1,18 & 1,87 & 1,38 \\
Araras & 13,42 & 1,13 & 1,81 & 1,33 \\
Pirassununga & 7,64 & 0,88 & 2,13 & 1,26 \\
\hline
\end{tabular}

Fonte: IBGE (2019).

\subsection{Aspectos Hidrogeológicos e Geológicos}

A ponderação dos parâmetros hidrogeológicos foi reali- zada a partir da análise de dados de 3.035 poços tubulares profundos disponíveis no Sistema de Informações de Águas Subterrâneas (SIAGAS, 2019) para os 93 mu- 
nicípios foco deste projeto.

Foram considerados para análise apenas os poços que apresentaram dados completos em relação à descrição geológica, perfil construtivo/instalação, ensaios de bombeamento com definição de parâmetros hidrodinâmicos (vazão, nível estático e dinâmico), selecionandose apenas 9\% (273 poços) de todos os dados disponíveis (Figura 2).

Observou-se que 39\% dos municípios não dispuseram de dados hidrogeológicos de poços tubulares profundos, e para suprir essa lacuna, foi realizada uma análise de distribuição espacial dos dados hidrogeológicos (vazão específica, espessura do aquífero e espessura da camada confinante) para toda a área de estudo, utilizando-se o método do inverso da distância ao quadrado no software ArcGIS, obtendo-se dessa maneira um valor unitário para cada parâmetro por município.

A densidade de poços (Figura 3B) na área variou de 0,0 a 387,60 poços $/ 100 \mathrm{~km}^{2}$, nos municípios de Torre de Pedra e Águas de São Pedro respectivamente, com média de 10,72 poços $/ 100 \mathrm{~km}^{2}$. 0 grande número de poços tubulares profundos perfurados na área (figuras $2 \mathrm{e}$ 3B) refletem a importância da água subterrânea para os munícipios com grande densidade populacional, como Ribeirão Preto, Araraquara, São Carlos e Rio Claro, que juntos representam 32\% da população total da área de estudo e estão entre os 6 munícipios de maior densidade de poços tubulares profundos (respectivamente 56,$84 ; 27,80 ; 21,99$ e 17,66 poços $/ 100 \mathrm{~km}^{2}$ ).

Municípios com densidades iguais ou inferiores a 2,67 poços $/ 100 \mathrm{~km}^{2}$ ( $1^{\circ}$ quartil), foram considerados "ótimos" (23 municípios), enquanto 23 municípios foram considerados "bons" e 47 municípios considerados "regulares" com densidade de poços superior 4,78 poços $/ 100 \mathrm{~km}^{2}$ (Figura 3B).

A capacidade específica (Q/s) na área de estudo (Figura 3D) variou entre 0,05 a $12,95 \mathrm{~m}^{3} / \mathrm{h} / \mathrm{m}$ nos municípios de Anhembi e Cravinhos, respectivamente com média de 2,03 m³/h/m. Foram considerados "ótimos" $23 \mathrm{mu}$ nicípios que obtiveram valores iguais ou superiores a $2,49 \mathrm{~m}^{3} / \mathrm{h} / \mathrm{m}$ (3 ${ }^{\circ}$ quartil), 23 municípios foram considerados "bons" e 47 municípios considerados "regulares" por apresentarem valores inferiores a 1,34 m³/h/m.

A distribuição espacial da capacidade específica aponta valores superiores no limite centro-oeste e noroeste dos municípios que possuem afloramentos de rochas do SAG, concordante com o contexto geológico local, caracterizado por maiores valores de espessura de aquífero (Figura 3F).

A espessura do SAG na área de estudo (Figura 3F) variou de 26 a 350 metros (municípios de Paranapanema e Luis Antônio respectivamente), com média de 150 metros, com maiores espessuras observadas no limite oeste (Figura 3F).

Assim como a capacidade específica, por tratar-se de um parâmetro indicativo de disponibilidade de água subterrânea, este foi tratado como prioritário e recebeu um peso superior para o ranqueamento preliminar. Foram considerados "ótimos" 23 municípios que obtiveram valores iguais ou superiores a 190,24 metros $\left(3^{\circ}\right.$ quartil); 23 municípios foram considerados "bons", e 47 municípios considerados "regulares" com espessuras médias inferiores a 137,88 (Figura 3F).

O grau de confinamento, representado pela espessura dos basaltos da Formação Serra Geral (Figura 3E), sobreposta ao aquífero na área de estudo, pode atingir até 395 metros (municípios de Cravinhos) tendo como a média de 45,58 metros, com distribuição espacial caracterizada pela ocorrência de menores espessuras no limite leste e central da área de aplicação deste modelo (Figura 3E).

Foram considerados “ótimos" 25 municípios que obtiveram valores entre 12 e 78,22 metros de espessura de basalto (entre $2^{\circ}$ e $3^{\circ}$ quartis), recebendo 7 pontos; 23 municípios foram considerados "bons", com pontuação de 4, e 45 municípios considerados "regulares" por apresentarem espessuras iguais e inferiores a 12 metros, recebendo uma pontuação de 3 (Figura 3E).

Os valores da recarga potencial média para os municípios que possuem afloramentos de rochas do SAG foram extraídos de (SANTAROSA et al., 2020), que utilizaram dados de satélites (Precipitação e Evapotranspiração) além de métodos empíricos para a estimativa do runoff e referem-se ao valor da recarga potencial média para o período de 2011 a 2016 (mm/ano), que variaram de 40,76 a 429,76 mm/ano (municípios de Barra Bonita e Ipeúna respectivamente), com média anual para a área de 231,34 mm (Figura 3C). 
Figura 3 - Distribuição estatística dos dados, categorização e potencialidade econômica, densidade de poços (poços/100km²), recarga ( $\mathrm{mm} / \mathrm{ano})$, capacidade específica ( $\left.\mathrm{m}^{3} / \mathrm{h} / \mathrm{m}\right)$, espessura de basalto ( $\mathrm{m}$ ) e espessura de aquífero $(\mathrm{m})$ nos municípios que possuem afloramentos de rochas do SAG no estado de São Paulo para a prospecção de águas minerais

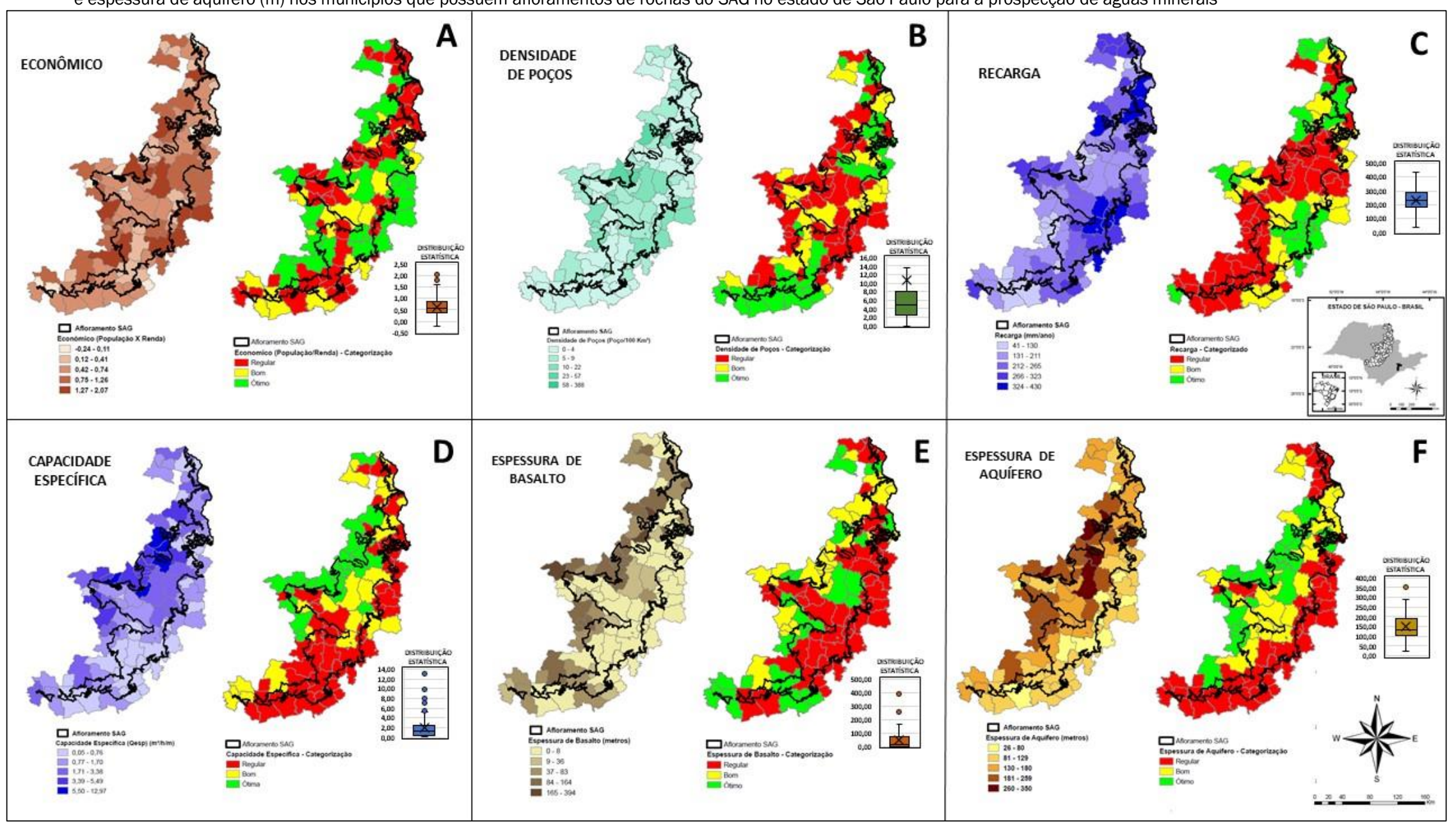


Foram considerados "ótimos" 23 municípios que obtiveram valores iguais ou superiores a $287,56 \mathrm{~mm} /$ ano $\left(3^{\circ}\right.$ quartil); 23 municípios foram considerados "bons", e 47 municípios considerados "regulares" com recarga potencial inferior a 233,90 mm/ano (Figura 3C).

\section{RESULTADOS E DISCUSSÕES}

O município de Ribeirão Preto foi o que apresentou maior potencial preliminar para a prospecção de águas minerais seguido pelos municípios de Nova Europa, Aramina, Batatais, Ibitinga e Jardinópolis, enquanto os municípios de Trabiju, Quadra e Porangaba obtiveram os menores valores. Foram considerados "ótimos" 16 municípios que obtiveram valores iguais ou superiores a 32 pontos ( $3^{\circ}$ quartil estatístico); 31 municípios foram considerados "bons" com pontuações entre 26 e 32, e por fim, 46 municípios considerados "regulares" por apresentarem pontuações iguais e inferiores a 26 (Figura 4).

Os 16 municípios que apresentaram maior potencial, encontram-se no limite centro-oeste e noroeste da área de aplicação do modelo (Figura 4). Estas, são as regiões que apresentam as maiores espessuras (Figura 3F), com maiores capacidades específicas (Figura 3D), além de maior grau de confinamento (Figura 3E). Por outro lado, observou-se que os municípios de menor potencial localizam-se em todo limite leste da área de aplicação do modelo (de norte a sul) (Figura 4), indicando também a conformidade com o modelo geológico/hidrogeológico por apresentarem menores espessura de aquífero ( $\mathrm{Fi}$ gura 3F), ausência ou baixa espessura de basalto (Figura $3 \mathrm{E}$ ) e finalmente, menor capacidade específica (Figura 3D).

Figura 4 - Distribuição estatística dos dados, categorização e potencialidade preliminar para os municípios que possuem afloramentos de rochas do Sistema Aquífero Guarani.

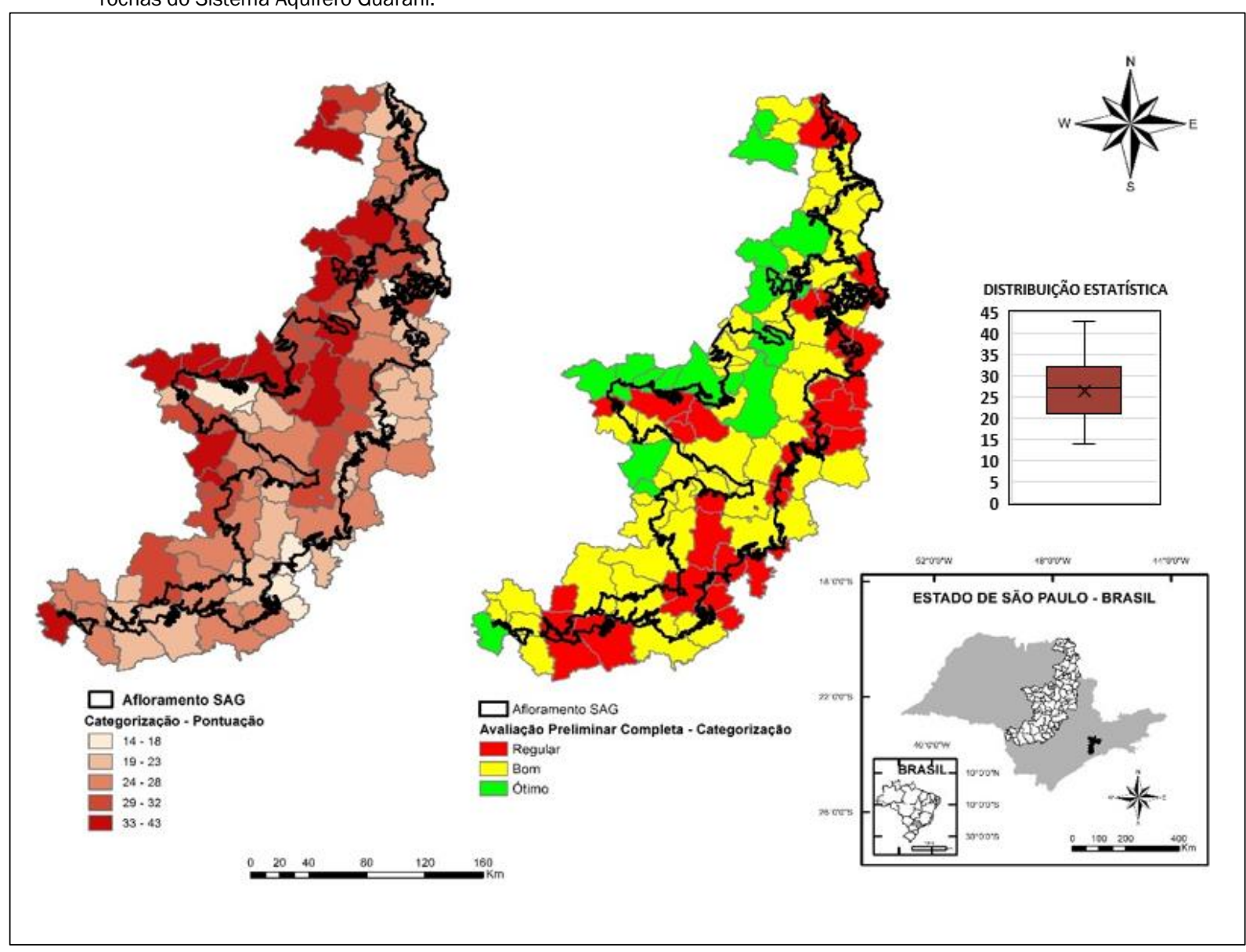

A avaliação do perfil hidroquímico e de qualidade da água subterrânea foi realizada a partir de 198 poços tubulares profundos, contemplando apenas 30 municípios na área de estudo, representando apenas cerca de $32 \%$ do total, analisadas pelo Instituto de Pesquisas Tecnológicas (IPT, 2011). De maneira semelhante aos dados apresentados anteriormente, para a maior representatividade, quando disponível mais de uma análise química para um determinado município, foi utilizada a média para a caracterização do parâmetro hidroquímico. 
Os valores de condutividade elétrica nos 30 municípios da área de estudo (Figura 5A) variaram de 8,60 a $144,33 \mu \mathrm{S} / \mathrm{cm}$ (municípios de Rincão e Serrana respectivamente) e média de 51,44 $\mu \mathrm{S} / \mathrm{cm}$.

Foram considerados "ótimos" 6 municípios com valores de condutividade elétrica entre 60 e $120 \mu \mathrm{S} / \mathrm{cm}$, enquanto 24 municípios foram considerados "bons", apresentando valores superiores a 120 ou inferiores a 60 $\mu \mathrm{S} / \mathrm{cm}$.

As concentrações de nitrato nos 30 municípios da área de estudo (Figura 5C) variaram de 0,05 a $8,55 \mathrm{mg} / \mathrm{L}$ (municípios de Serrana e Trabiju respectivamente) com média de 1,43 mg/L, com 25 municípios apresentando valores inferiores a $2,0 \mathrm{mg} / \mathrm{L}$, considerados "ótimos", quatro municípios foram considerados "bons" com concentrações entre $2,0 \mathrm{mg} / \mathrm{L}$ e $5,0 \mathrm{mg} / \mathrm{L}$ e apenas um município (Trabiju) apresentou concentrações superiores a $5,0 \mathrm{mg} / \mathrm{L}$ sendo considerado como "não aceitável" para fins de aproveitamento mineral.
A presença do íon fluoreto igual ou superior a 0,02 mg/L é requisito obrigatório nesta campanha exploratória, visto que este elemento caracteriza o aproveitamento da água subterrânea como um recurso mineral. Foi considerado a concentração máxima permitida de 1,50 $\mathrm{mg} / \mathrm{L}$ deste íon, visto o potencial risco deste elemento a saúde humana em concentrações elevadas, em consonância com as legislações vigentes de potabilidade (BRASIL, 2017).

Desta forma, foram considerados "ótimos" 23 munícipios que apresentaram concentrações entre 0,02 e $1,50 \mathrm{mg} / \mathrm{L}$, os municípios de Botucatu e Cajuru apresentaram concentrações abaixo de 0,02 mg/L, sendo considerados não aceitáveis para seu aproveitamento como mineral. Outros cinco municípios (Santa Rosa do Viterbo, Dois Córregos, São Pedro, Dourado e Bocaina) não obtiveram a análise de fluoreto realizada, desta forma, foram excluídos desta avaliação este parâmetro (Figura 5B).

Figura 5 - Distribuição estatística dos dados, categorização e potencialidade da condutividade elétrica $(\mu \mathrm{S} / \mathrm{cm})$, fluoreto $(\mathrm{mg} / \mathrm{L})$ e nitrato $(\mathrm{mg} / \mathrm{L})$ para os municípios que possuem afloramentos de rochas do Sistema Aquífero Guarani no estado de São Paulo

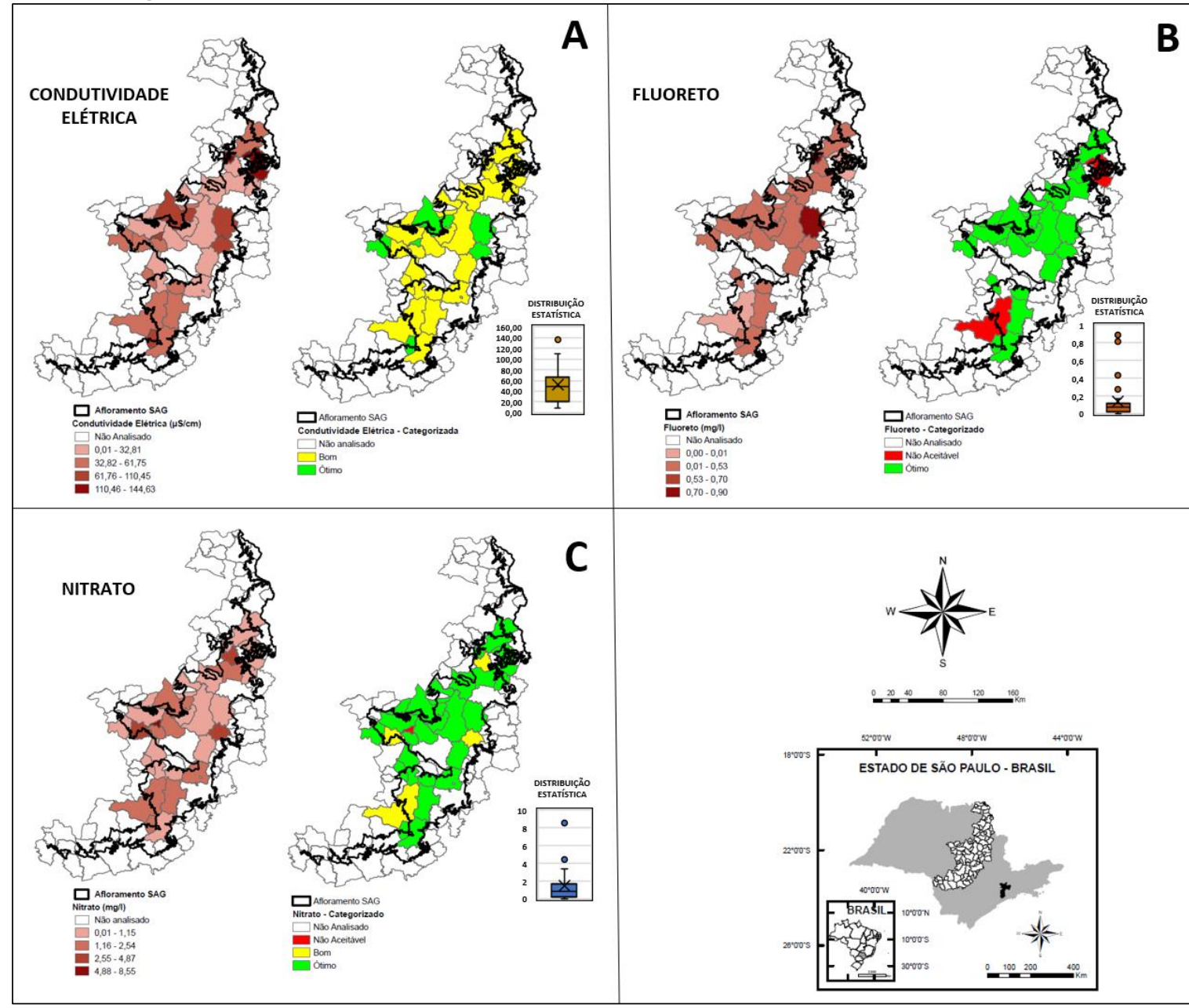


Os municípios de Araraquara, Bariri, Descalvado e Pardinho foram os que apresentaram maior potencial hidroquímico para águas minerais, sendo avaliados como "ótimos" em todos os parâmetros avaliados (condutividade elétrica, nitrato e fluoreto), totalizando 30 pontos (Figura 6).

Foram considerados "bons" 18 municípios (Figura 6) que obtiveram valores iguais ou superiores a 21 pontos e iguais ou inferiores que 26 ( $3^{\circ}$ quartil estatístico); foram considerados "regulares" 5 municípios (São Pedro,
Dois Córregos, Dourado, Santa Rosa do Viterbo e Bocaina), que apresentaram pontuações inferiores a 21 .

Já os municípios que apresentaram avaliações excludentes referentes ao íon fluoreto, abaixo de 0,02 mg/L, foram Botucatu e Cajuru, enquanto o município de Trabiju, apresentou os valores de nitrato acima do aceitável e desta forma os 3 municípios foram considerados como "não aceitáveis" para fim de potencial exploratório referente a hidroquímica (Figura 6).

Figura 6 - Distribuição estatística dos dados, categorização e potencialidade hidroquímica para os municípios que possuem afloramentos de rochas do Sistema Aquífero Guarani no estado de São Paulo para a prospecção de águas minerais

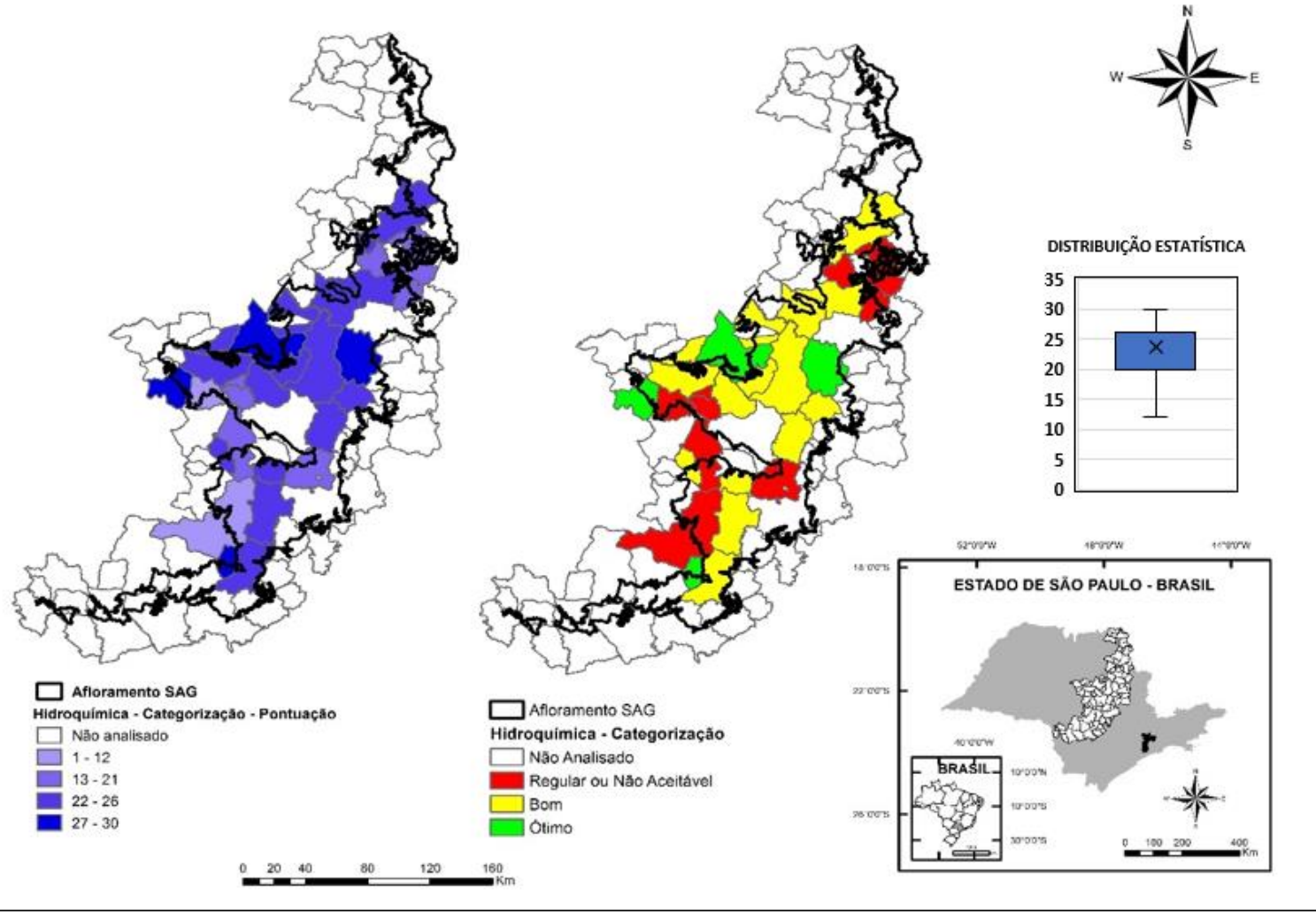

O ranqueamento final (Figura 7) levou em consideração a pontuação de cada município na avaliação preliminar (Figura 5) com o seu posterior refinamento (hidroquímica) (Figura 6). Desta forma, apenas os 30 munícipios com análises químicas, seguiram com esta avaliação final, que resultou em sete municípios considerados "ótimos" alvos exploratórios, com alto potencial para a exploração mineral (posterior pesquisa detalhada).

O município de Araraquara foi o que apresentou maior potencial exploratório seguido por Bariri, São Carlos, Gavião Peixoto, Descalvado, Serrana e Luís Antônio, totalizando respectivamente as seguintes pontuações 65 , 62, 61, 61 e 59 para os três últimos municípios. Estes sete municípios de maior potencial para águas minerais encontram-se no limite centro-oeste e central das áreas de afloramento do SAG (Figura 7), condizente com os modelos econômicos e geológico/hidrogeológico aqui propostos. Grande potencial econômico, alta capacidade hídrica e relativa proteção antrópica (presença de confinamento) podem ser atribuídos a estes sete municípios.

Já os municípios de Bocaina, Santa Rosa do Viterbo, Dourado, Botucatu, Cajuru e Trabiju obtiveram as piores pontuações, abaixo de 41, sendo considerados "regulares" na avaliação final. Os municípios de Cajuru e Botucatu apresentaram ausência de íon fluoreto e o município de Trabiju ocorrência de nitrato acima do aceitável (Figura 7). 
Figura 7 - Distribuição estatística, categorização final e definição de alvos potenciais para águas minerais dos municípios que possuem afloramentos de rochas do Sistema Aquífero Guarani no estado de São Paulo

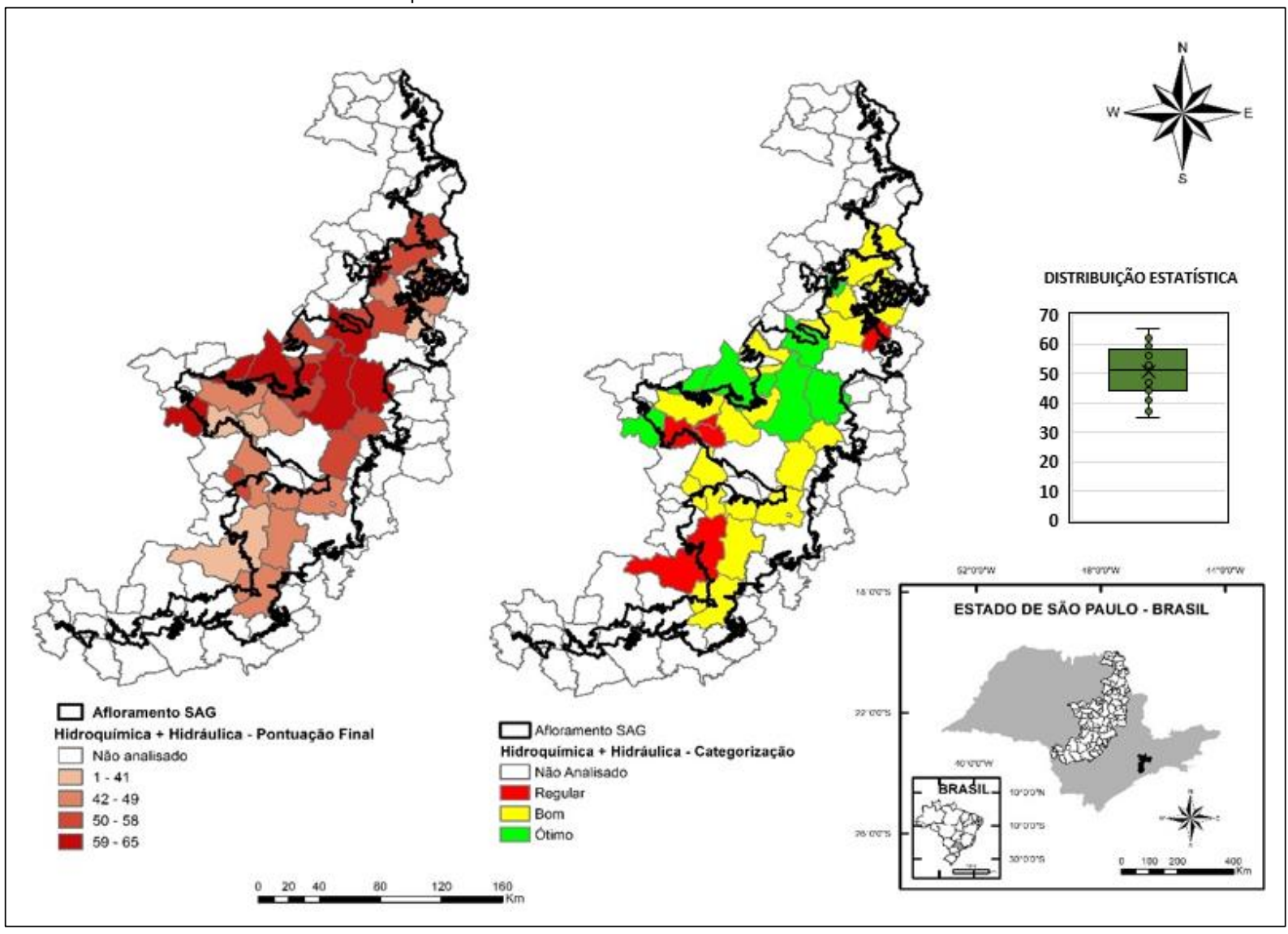

\section{CONCLUSÕES}

A avaliação preliminar considerou uma análise multicriterial aferindo pesos e notas aos diversos parâmetros analisados (Figura 4): econômico (População X Renda per Capita), hidroclimatológico (Recarga), hidrogeológico (Capacidade Específica e Densidade de Poços) e geológicos (Espessura de Aquífero e Grau de Confinamento), mostrando-se muito eficiente quando aplicado à área de estudo proposta. Os parâmetros geológicos, hidrogeológicos referentes à capacidade hídrica e proteção antrópica (capacidade específica, espessura de aquífero e grau de confinamento/espessura de basalto) formaram os pilares principais da avaliação preliminar sendo possível observar uma forte correlação entre eles.

Os 16 municípios de maior favorabilidade na etapa preliminar localizam-se no limite centro-oeste e noroeste da área de aplicação deste modelo (Figura 4), apresentando características condizentes com os modelos geológico/hidrogeológico regionais, onde ocorrem espessuras maiores de aquífero Formações Piramboia e Botucatu (média superior a 240 metros), maiores capacidades específicas (média de $5,14 \mathrm{~m}^{3} / \mathrm{h} / \mathrm{m}$ ), além de relativo grau de confinamento (entre 12 e 78 metros de es- pessura de basalto). Por outro lado, observou-se que os 26 municípios de menor favorabilidade (Figura 4), localizam-se em todo limite leste da área (norte a sul), também em conformidade com o modelo geológico/hidrogeológico regional, apresentaram menores espessura de aquífero (média de 94 metros), ausência ou baixo grau de confinamento (média de 9,50 metros de espessura de basalto) e, finalmente, menor capacidade específica (média de 0,54 m³/h/m).

A etapa de refinamento, considerou três parâmetros qualitativos, todos ligados à composição química das águas (condutividade elétrica, nitrato e fluoreto) considerados com os mesmos pesos e pontuações (Figura 5). Estes foram empregados para fins de definição de um perfil hidroquímico específico (mineralização), risco quanto a contaminação antrópica e vulnerabilidade (concentração de nitrato), além de seu aproveitamento mineral (presença do íon fluoreto em consonância com o Código de Águas Minerais.

A avaliação hidroquímica (refinamento), na área de trabalho foi limitada pelo número dados disponíveis, apenas 30 dos 93 municípios apresentaram análises químicas completas, possibilitando a aplicação desta fase em apenas $32 \%$ da área de trabalho. Desta forma, qua- 
tro municípios apresentaram classificação "ótimas" (Araraquara, Bariri, Descalvado e Pardinho) e três foram descartados, pela ausência de íon fluoreto (Cajuru e Botucatu) e por presença de nitrato acima do aceitável (Trabiju) (Figura 6).

Para a avaliação e ranqueamento final, os resultados das duas etapas (preliminar e avaliação hidroquímica) foram somadas. Apenas os 30 municípios com análises químicas disponíveis foram considerados, resultando em sete municípios alvos, com maior favorabilidade e potencial para projetos de água minerais, sendo eles: Araraquara, Bariri, São Carlos, Gavião Peixoto, Descalvado Serrana e Luís Antônio (Figura 7).

Ainda que efetivo e eficiente, o modelo de prospecção proposto acabou tornando-se restritivo em seu produto final, pois para a fase de refinamento $68 \%$ dos municípios foram descartados por não apresentarem análises químicas disponíveis, eliminando, por exemplo, os seis mais bem ranqueados na fase preliminar, (Ribeirão Preto, Nova Europa, Batatais, Jardinópolis, Ibitinga e Aramina). Assim, é importante ressaltar que o modelo pode apresentar limitações caso a base de dados utilizada não esteja robusta e completa.

Ainda que não aplicado em cenários socioeconômicos e aquíferos situados em outras regiões, espera-se que este modelo seja replicável a outras campanhas de prospecção hidrogeológica em outras unidades, cabendo ao usuário a adaptação ou inclusão de outros parâmetros às referências aqui propostas, como, por exemplo, intervalo de condutividade elétrica específico, grau de confinamento, $\mathrm{pH}$ ou outro elemento de aproveitamento mineral (como a temperatura ou outro íon/elemento digno de nota, por exemplo).

O modelo de prospecção foi aplicado a 93 municípios, porém pode ser aplicado a apenas um único município ou parte deste em diferentes escalas de trabalho, desde que o banco de dados para a área selecionada esteja disponível.

Os parâmetros exploratórios utilizados foram considerados eficientes e aplicáveis para uma proposta prospectiva hidrogeológica regional. Reforça-se ainda que os resultados obtidos são "alvos exploratórios regionais", devendo ser investigados em escala adequada (local), com ferramentas pontuais como a geofísica, perfuração de poços exploratórios, testes de bombeamento e análises hidroquímicas.

\section{REFERÊNCIAS}

AGÊNCIA NACIONAL DE MINERAÇÃO (ANM). Sumário Mineral 2018, Ano base 2017. 21/05/2020. Disponível em: http://www.anm.gov.br/. Acesso em: 04 jun. 2020.

BITYUKOVA L.; PETERSELL, V. - Chemical composition of bottled mineral waters in Estonia. Journal of Geochemical Exploration, $107, \quad$ p. 238-244, 2010. https://doi.org/10.1016/i.gexplo.2010.07.006

BRASIL. Decreto-Lei n ${ }^{\circ} 7.841$, de 8 de agosto de 1945. Código de Águas Minerais. In: BASTONE, P. e DUMONT. H. P. Legislação Mineral do Brasil, 1965. p. 107-122.

BRASIL. Decreto-lei $n^{\circ} 227$, de 28 de fevereiro de 1967. Código de Mineração. In: Código de Mineração e Legislação Correlata. Brasília: Departamento Nacional da Produção Mineral do Ministério de Minas e Energia, Ver., 1984. p. 22-54.

BRASIL. AGÊNCIA NACIONAL DE MINERAÇÃO (ANM). Disponível em: http://www.anm.gov.br/ Acesso em: 04 jun. 2020.

BRASIL. Ministério da Saúde. Portaria de Consolidação $n^{\circ} 5-$ Anexo XX, Consolidação das normas sobre as ações e os serviços de saúde do Sistema Único de Saúde. 2017.

BRASIL. Resolução da Diretoria Colegiada, $R D C n^{\circ} 274$, de 22 de setembro de 2005 - Regulamento Técnico para Águas Envasadas e Gelo, 2005a.

BRASIL. Resolução da Diretoria Colegiada, $R D C n^{\circ} 275$, de 22 de setembro de 2005 - Regulamento Técnico de Características Microbiológicas para Água Mineral Natural e Água Natural, 2005b.

BRASIL. Ministério da Saúde. Portaria de Consolidação $n^{\circ} 5$ Anexo XX, Consolidação das normas sobre as ações e os serviços de saúde do Sistema Único de Saúde, 2017.

BERTOLO, R. A., HIRATA R., FERNANDES A. - Hidrogeoquímica das águas minerais envasadas do Brasil. Revista ABAS, v. 37, n. 3, p. 515-529, 2007. https://doi.org/10.25249/03757536.2007373515529

BODIŠ, D.; KORDIK, J.; SLANINKA, I.; MALÍK, P.; LIŠČÁK, P.; PANÁK, D.; BOŽÍKOVÁ, J.; MARCIN, D. Mineral waters in Slovakia: evaluation of chemical composition stability using both historical records and the most recent data. Journal of Geochemical Exploration, v. 107, p. 382-390, 2010.

BONOTTO, D.M. - 222Rn, 220Rn and other dissolved gases in mineral waters of southeast Brazil. J. Environ. Radioact, v. 132, p.21 e 30, 2014. https://doi.org/10.1016/i.jenvrad.2014.01.005

CAETANO-CHANG, M.R. A Formação Piramboia no centro-leste do estado de São Paulo. Tese (Doutorado) - Instituto de Geociências e Ciências Exatas - Rio Claro, Universidade Estadual Paulista (UNESP), Rio Claro, 1997.

CAGNON F. \& HIRATA R. - Source of nitrate in the groundwater of Adamantina aquifer in Urânia, SP - Brazil. In: INTERNATIONAL ASSOCIATION OF HYDROGEOLOGISTS, IAH CONGRESS, 33., 2004. [Proceedings...] ALHSUD, 7, Zacatecas, México, atas, CD. 2004 
CPRM - SERVIÇO GEOLÓGICO DO BRASIL. Sistema de Informações de Águas Subterrâneas - SIAGAS. Rio de Janeiro, 2019. Disponível em: http://siagasweb.cprm.gov.br/layout/ Acesso em: 23 out. 2019.

DAEE - DEPARTAMENTO DE ÁGUAS E ENERGIA ELÉTRICA DO ESTADO DE SÃO PAULO. Estudo de Águas Subterrâneas. Região Administrativa 6. Ribeirão Preto. São Paulo: DAEE, Volume 2. (Texto). 1974.

DAEE - DEPARTAMENTO DE ÁGUAS E ENERGIA ELÉTRICA, UNESP - UNIVERSIDADE ESTADUAL PAULISTA. Mapa Geológico do Estado de São Paulo (1:250.000). 1984.

DAEE - DEPARTAMENTO DE ÁGUAS E ENERGIA ELÉTRICA. Banco de Dados Hidrológicos. São Paulo: DAEE, 2020. Disponível em: http://www.hidrologia.daee.sp.gov.br/,2020.

DAEE/IG/IPT/CPRM. Mapa de Águas Subterrâneas do Estado de São Paulo. Escala 1:1.000.000. Nota explicativa. São Paulo. São Paulo: DAEE, 3 v. (mapa e CD-ROM). 2005.

FEITOSA, F.A.C; MANOEL FILHO, J. - Hidrogeologia: Conceitos e Aplicações. 3. ed. Rio de Janeiro: CPRM/LABHID, 2008.

GARPELLI, L. N.; GASTMANS, D. Potencial Hidromineral dos Aquíferos do Estado de São Paulo 2020. https://doi.org/10.22456/1807-9806.109987

GASTMANS, D.; REIS, M.M.; CHAN, H.K. - Geotermometria das águas hipertermais do Sistema Aquífero Guarani no Estado de São Paulo. Revista Brasileira de Geociências, p. 208-225, 2012.

HEALY, R.W. Estimating Groundwater Recharge. 1. ed. Cambridge: Cambridge University Press. 2010. https://doi.org/10.1017/CB09780511780745

IBGE - INSTITUTO BRASILEIRO DE GEOGRAFIA E ESTATÍSTICA. Estimativas da População Residente no Brasil e Unidades da Federação com Data de Referência em $1^{\circ}$ de julho de 2019.

IPT - INSTITUTO DE PESQUISAS TECNOLÓGICAS. Subsídios ao Plano de Desenvolvimento e Proteção Ambiental da área de afloramento do Sistema Aquífero Guarani no Estado de São Paulo (Coordenação geral José Luiz Albuquerque Filho). São Paulo. 2011.

LYUBOMIROVA, V.; MIHAYLOVA, V.; DJINGOVA, R. - Chemical characterization of Bulgarian bottled mineral Waters. Journal of Food Composition and Analysis, 93, 103595, 2020. https://doi.org/10.1016/j.jfca.2020.103595

LOURENÇO, C.; RIBEIRO, L.; CRUZ, J. - Classification of natural mineral and spring bottled waters of Portugal using Principal Component Analysis. Journal of Geochemical Exploration, $v$. 107, p. 362-372, 2010. https://doi.org/10.1016/i.gexplo.2010.08.001

MARANHÃO, R. J.L. Introdução a prospecção mineral. BNB/ETENE, Fortaleza, 3º. Ed., 1985.

MELFI A.J.; MISI A.; CAMPOS D.A.; CORDANI U.G. (orgs.). Recursos Minerais no Brasil: problemas e desafios. Academia Brasileira de Ciências, Rio de Janeiro, 2016.

MUELLER, D. K. \& HELSEL, D.R. Nutrients in the Nation's Wa ters: too much of a good thing?: U.S. Geological Survey Circular
1136. Documento disponivel em

http://water.usgs.gov/nawqa/circ-1136/circ-1136main.htm. 1996.

PAULA E SILVA, F., CHANG, H. K., CAETANO-CHANG, M. R., SINELLI, O. Arcabouço geológico e hidrofácies do Sistema Aquífero Guarani, no município de Ribeirão Preto (SP). Revista Brasileira de Geociências, v. 38, n. 1, p. 56-67, 2008. https://doi.org/10.25249/0375-7536.20083815667

PEATE, D. W.; HAWKESWORTH, C. J.; MANTOVANI, M. S. M. Chemical stratigraphy of the Paraná lavas (South America): classification of magma types and their spatial distribution. Bulletin of Volcanology, v. 55, n. 1-2, p. 119-139, 1992. https://doi.org/10.1007/BF00301125

PEREIRA, R. M. Fundamentos de prospecção mineral. Rio de Janeiro: Interciência, 2003.

PNUD - PROGRAMA DAS NAÇÕES UNIDAS PARA O DESENVOLVIMENTO. Índice de Desenvolvimento Humano Municipal Brasileiro. - Brasília: PNUD, Ipea, FJP, 2013. 96 p.

QUEIROZ, E.T. Diagnóstico das águas minerais e potáveis de mesa do Brasil. Brasília, DF. Departamento Nacional de Produção Mineral, Diretoria de Fiscalização da Atividade Minerária, 2015

REIS, M. M. Potencial hidrotermal das águas hipertermais do Sistema Aquífero Guarani no Estado de São Paulo. Dissertação (Mestrado) - Instituto de Geociências e Ciências Exatas, Universidade Estadual Paulista "Júlio de Mesquita Filho". Rio Claro, 2001.

RODWAN JR., J. G. Bottled Water 2019: significant, but slower, growth for bottled water in 2018, in bottled water reporter. IBWA, International Bottled Water Association, 2019. Disponível em: https://www.bottledwater.org/. Acesso em: 11 nov. 2019.

SANTAROSA, L.; GASTMANS, D.; SITOLINI, T.P.; KIRCHHEIM, R.E.; BETANCUR, S.B.; OLIVEIRA, M.E.D.; CAMPOS, J.C.V.; MANZIONE, R.L. Assessment of Groundwater Recharge along the Guarani Aquifer System Outcrop Zone in São Paulo State (Brazil): an important tool towards integrated management, 2020. (Aceito no Environmental Earth Science Journa para publicação). https://doi.org/10.1007/s12665-021-09382-3

SANTOS, M. M.; CAETANO CHANG, M. R.; CHANG, H.K. - Análise do balanço hídrico climatológico do Sistema Aquífero Guarani, em sua área de afloramento no Estado de São Paulo. Revista Brasileira de Climatologia, v. 10, p. 153-170, 2012. https://doi.org/10.5380/abclima.v10i1.30596

SCANLON, B.R.; HEALY, R.W.; COOK, P.G. Choosing appropriate techniques for quantifying groundwater recharge. Hydrogeology Journal, v. 10, p. 18-39. 2002 https://doi.org/10.1007/s10040-001-0176-2

SILVA, R.B.G. da. Estudo Hidroquímico e isotópico do Aquífero Botucatu no Estado de São Paulo, 1983. 133p. Tese (Doutorado em Geologia) - Instituto de Geociências - Universidade de São Paulo, São Paulo, 1983.

VIRGÍLIO CRUZ, J.; FREIRE, P.; COSTA, A. Mineral waters characterization in the Azores archipelago (Portugal). Journal of Volcanology and Geothermal Research, v. 190, p. 353-364, 2010. https://doi.org/10.1016/j.jvolgeores.2009.12.001 